\title{
COVID-19 and Cardiomyopathy: A Systematic Review
}

\begin{abstract}
Fatemeh Omidi ${ }^{*}$, Bahareh Hajikhani ${ }^{2 *}$, Seyyedeh Neda Kazemi ${ }^{3}$, Ardeshir Tajbakhsh ${ }^{4}$, Sajedeh Riazi ${ }^{5}$, Mehdi Mirsaeidi ${ }^{6}$, Ali Ansari ${ }^{7}$, Masoud Ghanbari Boroujeni ${ }^{7}$, Farima Khalili ${ }^{7}$, Sara Hadadi ${ }^{6}$ and Mohammad Javad Nasiri ${ }^{2 *}$

${ }^{1}$ Department of Cardiology, Imam Hossein Hospital, Shahid Beheshti University of Medical Sciences, Tehran, Iran, ${ }^{2}$ Department of Microbiology, School of Medicine, Shahid Beheshti University of Medical Sciences, Tehran, Iran, ${ }^{3}$ Preventative Gynecology Research Center, Imam Hossein Hospital, Shahid Beheshti University of Medical Sciences, Tehran, Iran, ${ }^{4}$ Anesthesiology Research Center, Imam Hossein Hospital, Shahid Beheshti University of Medical Sciences, Tehran, Iran, ${ }^{5}$ Imam Hossein Hospital, Shahid Beheshti University of Medical Sciences, Tehran, Iran, ${ }^{6}$ Department of Pulmonary and Critical Care, University of Miami Miller School of Medicine, Miami, FL, United States, ${ }^{7}$ School of Medicine, Shahid Beheshti University of Medical Sciences, Tehran, Iran
\end{abstract}

\section{OPEN ACCESS}

Edited by:

Reza Beigverdi,

Tehran University of Medical

Sciences, Iran

Reviewed by:

Roshan Dinparastisaleh,

The Johns Hopkins Hospital,

United States

Yu-Che Lee,

University at Buffalo, United States

*Correspondence:

Bahareh Hajikhan

b.hajikhani@gmail.com

Fatemeh Omidi

dr.fateme.omidi@gmail.com

Mohammad Javad Nasiri

mj.nasiri@hotmail.com

Specialty section:

This article was submitted to

Cardiovascular Epidemiology and

Prevention,

a section of the journal

Frontiers in Cardiovascular Medicine

Received: 14 April 2021

Accepted: 21 May 2021

Published: 17 June 2021

Citation:

Omidi F, Hajikhani B, Kazemi SN, Tajbakhsh A, Riazi S, Mirsaeidi M, Ansari A, Ghanbari Boroujeni M, Khalili F, Hadadi S and Nasiri MJ (2021) COVID-19 and Cardiomyopathy: A Systematic

Review.

Front. Cardiovasc. Med. 8:695206.

doi: 10.3389/fcvm.2021.695206
Background: Cardiomyopathies (CMPs) due to myocytes involvement are among the leading causes of sudden adolescent death and heart failure. During the COVID-19 pandemic, there are limited data available on cardiac complications in patients with COVID-19, leading to severe outcomes.

Methods: We conducted a systematic search in Pubmed/Medline, Web of Science, and Embase databases up to August 2020, for all relevant studies about COVID-19 and CMPs.

Results: A total of 29 articles with a total number of 1460 patients were included. Hypertension, diabetes, obesity, hyperlipidemia, and ischemic heart disease were the most reported comorbidities among patients with COVID-19 and cardiomyopathy. In the laboratory findings, $21.47 \%$ of patients had increased levels of troponin. Raised D-dimer levels were also reported in all of the patients. Echocardiographic results revealed mild, moderate, and severe Left Ventricular (LV) dysfunction present in 17.13, 11.87, and 10\% of patients, respectively.

Conclusions: Cardiac injury and CMPs were common conditions in patients with COVID-19. Therefore, it is suggested that cardiac damage be considered in managing patients with COVID-19.

Keywords: COVID-19, cardiomyopathy, cardiac injury and regeneration, systematic review, SARS-CoV-2

\section{INTRODUCTION}

The emergence of severe acute respiratory syndrome coronavirus 2 (SARS-CoV-2), which was first reported on 31 December 2019 from Wuhan, China, resulted in an unprecedented outbreak of Coronavirus disease 2019 (COVID-19). The most common manifestation of COVID-19 is pulmonary complications. However, this novel disease's presentations have a broad spectrum of signs and symptoms from asymptomatic infection or mild flu-like symptoms to multiorgan failure resulting in death $(1,2)$. Cardiovascular disease (CVD) has been reported in patients infected with COVID-19 (3). Based on the literature, 20-30\% of hospitalized patients showed cardiovascular manifestations associated with worse outcomes $(4,5)$. Cardiovascular complications of COVID-19 
are thought to be a combination of direct viral injury and the host's immune response resulting in vascular inflammation, plaque instability, and myocardial inflammation (6-9). Cardiomyopathies (CMPs) which resulted from heart muscle involvement, are among the main causes of adolescent sudden death and heart failure (10). SARS-CoV-2 infection in patients suffering from CMPs represents an actual risk of exacerbating patient clinical status (11).

Although many authors have reported various aspects of respiratory-related symptoms of COVID-19, the increasing prevalence of cardiac complications in COVID-19 patients should be taken into considerations (12-17). Thus, this study was aimed to systematically review the current published literature to evaluate clinical and paraclinical characteristics of CMPs in patients infected with SARS-CoV-2.

\section{METHODS}

\section{Search Strategy}

In the following bibliographic databases, we carried out a comprehensive systematic search of literature: PubMed/Medline, Embase, and Web of Science. We searched for any relevant articles published in English up to August 2020. The search included keywords including COVID-19, severe acute respiratory syndrome coronavirus 2, SARS-CoV-2, in combinations with cardiomyopathy, or CMP, cardiomyopathies, myocardiopathy, cardiac injury, or myocarditis.

Additionally, all references of selected papers were searched manually for additional related articles. The present systematic review conforms to the "Preferred Reporting Items for Systematic Reviews and Meta-Analyses" (PRISMA) statement (18).

\section{Study Selection}

Studies reported any data about CMPs in patients with confirmed COVID-19 were included. Abstracts, commentary, letter to editor, guidelines, and review articles were excluded.

All retrieved publications were screened for eligibility in two phases. First, two reviewers independently screened the titles and abstracts of potentially relevant articles identified in the primary search. Subsequently, a review of the full texts of all remaining articles was done by the same authors. Any discrepancy in the article selection or technical uncertainties were discussed and resolved between review authors.

\section{Data Extraction}

The following variables were extracted from all included studies: first author, year of publication, type of study, country where the research was conducted, study population, COVID-19 diagnosis technique, laboratory findings, treatment protocols, and type of CMPs. Two authors independently extracted the data from the selected studies. The data was jointly reconciled, and disagreements were discussed and resolved between review authors.

\section{RESULTS}

As shown in Figure 1, a total of 186 studies were identified from databases. After removing 45 duplicates, 141 non-duplicate studies remained for further assessments. After applying the inclusion/exclusion criteria, 29 articles (22 case reports and 7 case series) were included with a total number of 1460 unique cases of COVID-19 with a mean age of 58 years. The characteristics of the included studies are described in Table 1.

Table 2 shows the outcomes and prognosis of CMPs in patients with COVID-19. 98 out of 1,212 evaluated patients developed cardiogenic shock (8.08\%). Six studies reported mortality rates, showing 48 out of 192 (25\%) of patients deceased.

As presented in Table 3, hypertension, diabetes, obesity, hyperlipidemia, ischemic disease, and obstructive sleep apnea were the most reported comorbidities among them.

As shown in Table 3, cough and fever were reported as the most prevalent symptoms in 14 out of 29 studies. Dyspnea was reported in 9 studies. According to these studies, $90 \%$ of the evaluated patients had this complication. Evaluation of laboratory findings showed elevated troponin levels in 18 studies with 308 out of 1,412 patients $(21.47 \%)$. Increased D-dimer levels were reported in 5 case reports, of which six patients showed this elevated marker.

CMPs evidence in patients with COVID-19 indicates in Table 4. Common ECG findings were: tachycardia, premature beats, ST-segment elevation, blocks, and inverted $\mathrm{T}$ wave. Inverted $\mathrm{T}$ waves were seen in EKG findings of 9 studies (91.66\% of evaluated patients). Left ventricular (LV) involvement is a hallmark of primary CMPs. Echocardiographic findings revealed mild (17.1\%), moderate $(11.85 \%)$, and severe (9.98\%) LV dysfunction, which was discussed in 6, 4, and 11 studies, respectively. Aneurysm formation, a sign of stress-induced cardiomyopathy followed COVID19 , was found in all 11 evaluated patients (100\%). Regional wall motion abnormalities (RWMA) as another sign were found in 46/1,217 (1.15\%) patients. Right ventricular (RV) involvement and high pulmonary artery pressure (PAP) are signs of the destruction of the right heart. RV enlargement was presented in $14.88 \%$ of tested patients $(181 / 1,216)$. RV dysfunction was also found in $26.01 \%(315 / 1,211)$ of patients' echocardiograms. Findings of Chest X-Ray (CXR) and Chest CT scan showed ground-glass opacification (GGO) patterns (26 of 34 patients) and consolidation (7 of 7 patients) as the most common findings (Table 4). Among the type of CMPs, COVID CMPs, and hypertrophic cardiomyopathy were among the most reported type in 39.13 and $18.75 \%$ cases, respectively.

In terms of treatment, 10 out of 14 patients (71.42\%) reported in 11 studies received $\beta$-Blocker as part of their treatment regimen. The use of Diuretic agents was reported in 7 studies which included 7 out of $9(77.77 \%)$ patients (Table 5).

\section{DISCUSSION}

COVID-19 has resulted in other organ involvement, and CMPs are among the most significant complications of this rapidly 


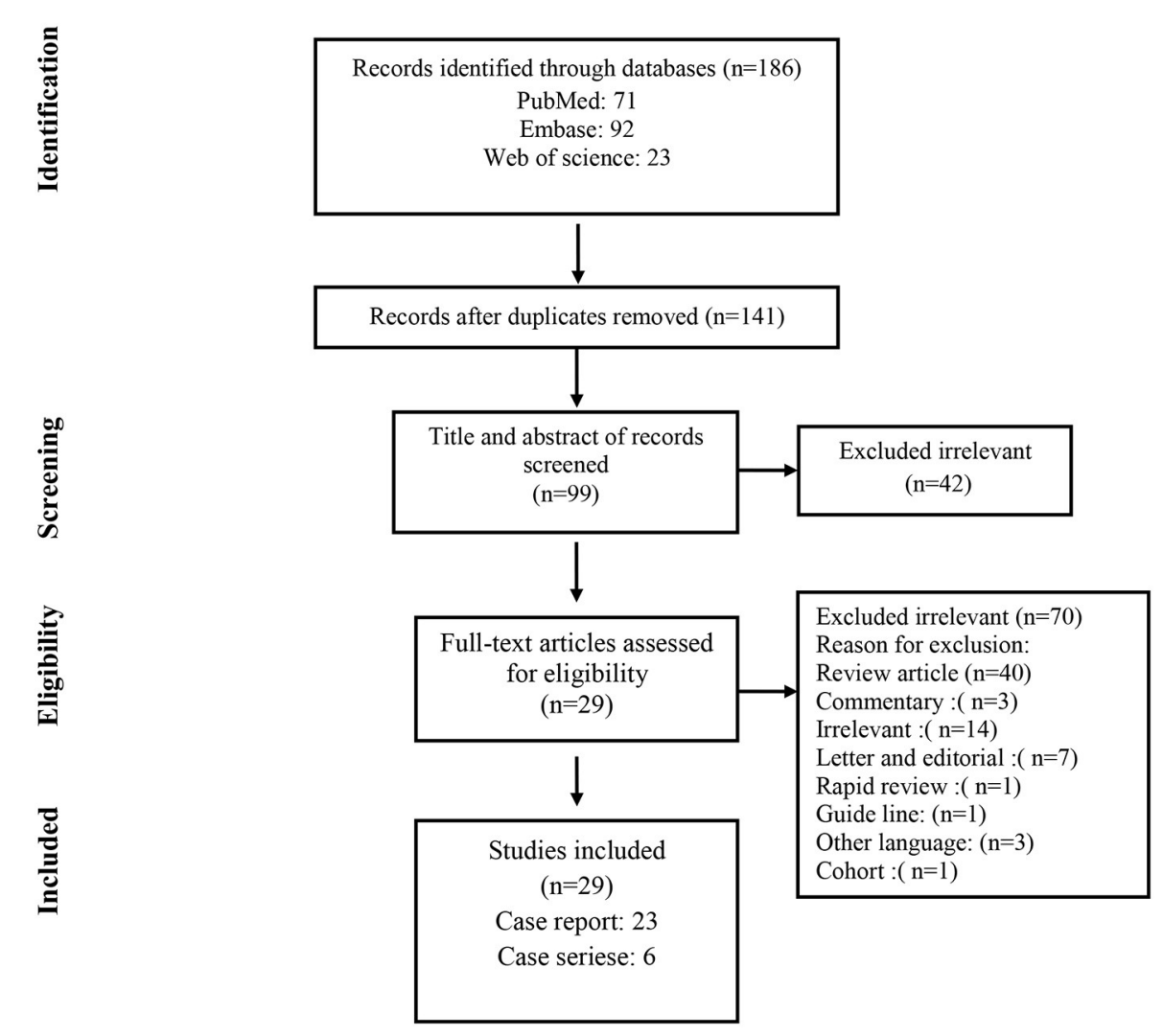

FIGURE 1 | Flow chart of study selection for inclusion in the systematic review.

emerging disease, causing more severe disease and increased mortality rates $(48,49)$. In this systematic review, we studied the cardiac injuries in patients with SARS-CoV-2 infection that resulted in CMPs. Echocardiographic results showed a range of mild to severe left ventricular dysfunction in $10 \%$ to $17.13 \%$ of the studied patients.

The patients' recovery and death rates were assessed in 20 studies that showed that $28.7 \%$ of patients with one type of CMPs died following SARS-CoV-2 infection. Patients with cardiovascular comorbidities had a higher risk of developing cardiac injury (50).

In a study on twenty-one critically ill patients admitted in intensive care units (ICU), one-third developed CMPs (51). Yang et al. showed 52 critically ill COVID-19 patients 12 (23\%) presented with cardiac injury (52).

The results of a cohort study showed that $23 \%$ of patients experienced new heart failure or exacerbation of chronic heart failure, of which 28 survived, and 16 died (50).

Based on the included studies that examined patients' mortality rate with CMPs and COVID-19, 25\% of these patients were deceased. As a result, it can be inferred that cardiac injury is a significant predisposing factor for increasing the mortality rate of COVID-19.

Huang et al. demonstrated a "Cytokine storm" model that results in a pro-inflammatory markers surge that may lead to myocardial injury (53). Similar effects have been observed with MERS-CoV and SARS-CoV infections previously (54). Furthermore, the virus may be involved in a primary myocardial injury by entering the myocytes through the ACE-2 receptor (55).

Overall, SARS-CoV-2 can cause cardiac complications through the following pathways: (1) Indirect cardiac injury due to increased release of cytokines and inflammatory pathways. (2) Direct invasion of the SARS-COV-2 in cardiac myocytes. (3) Respiratory damage can cause hypoxia, myocardial supplydemand mismatch, followed by oxidative stress and damage to cardiomyocytes $(56,57)$.

There are different manifestations of cardiac involvement in COVID-19, including acute myocardial infarction, acute heart failure, cardiogenic shock, myocarditis, and fatal arrhythmias (58). Myocardial injury is a common condition in COVID19 hospitalized, which is characterized by increased troponin levels (59). Another definition of cardiac injury is reported as abnormality in cardiac biomarkers, electrocardiography, or echocardiography relative to the patient's previous condition. In a cohort study of 416 patients, $19.7 \%$ of hospitalized patients had a cardiac injury (34).

Cardiomyopathy was defined as evidence of new left ventricular systolic dysfunction on trans-thoracic echocardiography with one of the following criteria: 1. Clinical signs of cardiogenic shock, 2. Increase in creatine kinase or troponin level, and 3. Reduction in oxygen saturation of the central vein below 70\% (43). 
TABLE 1 | Characteristics of the included studies.

\begin{tabular}{|c|c|c|c|c|c|}
\hline References & Country & Type of study & No. of patients & Male/female & Mean age \\
\hline Doyen et al. (19) & Italy & Case report & 1 & $1 \mathrm{M}$ & 69 \\
\hline Paul et al. (20) & France & Case report & 1 & $1 \mathrm{M}$ & 35 \\
\hline Huyut (21) & Turkey & Case report & 1 & $1 F$ & 59 \\
\hline Pasqualetto et al. (22) & Italy & Case series & 3 & $2 M-1 F$ & 83.33 \\
\hline Deng et al. (23) & China & Case series & 14 & $10 \mathrm{M}-4 \mathrm{~F}$ & 74 \\
\hline Taza et al. (24) & USA & Case report & 1 & $1 \mathrm{M}$ & 52 \\
\hline Roca et al. (25) & Italy & Case report & 1 & $1 F$ & 87 \\
\hline Minhas et al. (26) & USA & Case report & 1 & $1 \mathrm{~F}$ & 52 \\
\hline Juusela et al. (27) & USA & Case series & 2 & $2 F$ & 35.5 \\
\hline Meyer et al. (28) & Switzerland & Case report & 1 & $1 \mathrm{~F}$ & 83 \\
\hline Khalid et al. (29) & Italy & Case report & 1 & $1 F$ & 76 \\
\hline Nguyen et al. (30) & Belgium & Case report & 1 & $1 F$ & 71 \\
\hline Bonnet et al. (31) & France & Case report & 1 & $1 \mathrm{M}$ & 27 \\
\hline Zhang et al. (32) & Multicenter & Case series & 2 & $1 \mathrm{M}-1 \mathrm{~F}$ & 59 \\
\hline Dabbagh et al. (33) & USA & Case report & 1 & $1 F$ & 67 \\
\hline Guo et al. (34) & China & Case series & 187 & $91 \mathrm{M}-96 \mathrm{~F}$ & 58.5 \\
\hline Tavazzi et al. (35) & Italy & Case report & 1 & $1 \mathrm{M}$ & 69 \\
\hline Hua et al. (36) & UK & Case report & 1 & $1 \mathrm{M}$ & 47 \\
\hline Villanueva et al. (37) & USA & Case report & 1 & $1 \mathrm{M}$ & 68 \\
\hline Kir et al. (38) & USA & Case report & 1 & $1 \mathrm{M}$ & 49 \\
\hline Dweck et al. (39) & Multicenter & Case series & 1209 & 844 M-365 F & 62 \\
\hline Irabien-Ortiz et al. (40) & Spain & Case report & 1 & $1 \mathrm{M}$ & 59 \\
\hline Craver et al. (41) & USA & Case report & 1 & $1 \mathrm{M}$ & 17 \\
\hline Bobeck et al. (42) & USA & case report & 1 & $1 \mathrm{M}$ & 80 \\
\hline Arentz et al. (43) & USA & Case series & 21 & $10 \mathrm{M}-11 \mathrm{~F}$ & 70 \\
\hline $\begin{array}{l}\text { Yildirim and Karaagac } \\
\text { (44) }\end{array}$ & Turkey & Case report & 1 & $1 \mathrm{~F}$ & 7 \\
\hline Chadha (45) & USA & Case report & 1 & $1 F$ & 85 \\
\hline Kim et al. (46) & Korea & Case report & 1 & $1 F$ & 21 \\
\hline Luetkens et al. (47) & Germany & Case report & 1 & $1 \mathrm{M}$ & 79 \\
\hline
\end{tabular}

TABLE 2 | The outcomes and prognosis of CMPs.

\begin{tabular}{lccc}
\hline Outcomes & No of study & $\boldsymbol{n} / \mathbf{N}$ & Percentage (\%) \\
\hline Deceased & 6 & $48 / 192$ & 25 \\
Cured & 13 & $14 / 16$ & 87.5 \\
Prognosis & 4 & & 8.08 \\
Cardiogenic shock & 3 & $98 / 1,212$ & 42.40 \\
MOD $^{\text {a }}$ & 8 & $81 / 191$ & 31.16 \\
ARDS $^{\text {b }}$ & & $67 / 215$ & \\
\hline
\end{tabular}

$n$, number of patients with any variables; $N$, the total number of studied patients. ${ }^{a} \mathrm{MOD}, \mathrm{Multi}$ organ disease; ${ }^{b} \mathrm{ARDS}$, Adult respiratory distress syndrome.

Our results showed that ARDS was present in $31.45 \%$ of patients following COVID-19 and cardiomyopathy. The cardiogenic shock occurred in $8 \%$ of patients. Reported data from Germany and the United States $(56,60)$ showed that cardiogenic shock is a significant complication of COVID-19. According to the evaluated studies in our systematic review, $\sim 8 \%$ of patients developed heart failure/cardiogenic shock as a manifestation of COVID-19.
We showed that common symptoms of COVID-19 in patients with cardiac injury include fever, cough, headache, and fatigue. These findings are broadly consistent with other studies examining clinical signs in patients with COVID-19 $(13,14)$.

Our review of published studies showed the most common abnormal laboratory findings in patients with cardiomyopathy were increased IL-6 level, elevated ferritin, and High D-dimer. Some studies were reported that Serum concentrations of IL6 were higher in severe cases of COVID-19 compared with moderate cases. Moreover, in deceased patients, levels of this cytokine were substantially higher than in recovered ones. So, continuous measurement of IL-6 level for early prediction of severity of infection has been suggested $(61,62)$.

The elevated level of fibrin degradation products, especially D-dimers $\left(>2590 / \mathrm{ng} \cdot \mathrm{mL}^{-1}\right)$, was shown to be an indicator of pulmonary embolism in hospitalized COVID-19 patients. It also contributed to poor prognosis and high mortality in patients with a more severe form of COVID-19 (63).

Our systematic review showed that $21.7 \%$ of patients presented with high troponin levels that were investigated in 14 studies. Gue et al. indicated the importance of monitoring 
TABLE 3 | Clinical and laboratories findings in patients with COVID-19.

\begin{tabular}{|c|c|c|c|c|}
\hline & Variable & No of study & $n / N$ & $\%$ \\
\hline \multirow{10}{*}{$\begin{array}{l}\text { Clinical } \\
\text { manifestations }\end{array}$} & Chest pain & 9 & 128/1,232 & 10.38 \\
\hline & Dyspnea & 9 & $9 / 10$ & 90 \\
\hline & $\begin{array}{l}\text { Shortness } \\
\text { of breath }\end{array}$ & 11 & $39 / 45$ & 88.66 \\
\hline & Cough & 14 & $38 / 49$ & 77.55 \\
\hline & Fever & 14 & $40 / 51$ & 78.43 \\
\hline & Fatigue & 5 & $5 / 5$ & 5 \\
\hline & Tachypnea & 7 & $8 / 21$ & 30.09 \\
\hline & Crackles & 7 & $7 / 8$ & 87.5 \\
\hline & Diarrhea & 3 & $3 / 3$ & 100 \\
\hline & $\begin{array}{l}\text { Nausea \& } \\
\text { vomiting }\end{array}$ & 4 & $5 / 6$ & 83.33 \\
\hline \multirow[t]{2}{*}{ Signs } & $\begin{array}{l}\text { Elevated } \\
\text { pulse rate }\end{array}$ & 12 & 195/1,413 & 13.8 \\
\hline & $\begin{array}{l}\text { Elevated } \\
\text { temperature }\end{array}$ & 12 & $32 / 33$ & 96.96 \\
\hline \multirow[t]{9}{*}{ Comorbidities } & Hypertension & 15 & $526 / 1,424$ & 36.93 \\
\hline & Diabetes & 10 & $279 / 1,440$ & 19.37 \\
\hline & Obesity & 3 & $11 / 17$ & 64.7 \\
\hline & Hyperlipidemia & 5 & $5 / 5$ & 100 \\
\hline & $\begin{array}{l}\text { Ischemic } \\
\text { disease }\end{array}$ & 4 & $200-1,431$ & 13.97 \\
\hline & $\begin{array}{l}\text { Obstructive } \\
\text { sleep apnea }\end{array}$ & 2 & $10 / 35$ & 25.57 \\
\hline & $\mathrm{COPD}^{\mathrm{a}}$ & 3 & 12/222 & 5.4 \\
\hline & $C K D^{b}$ & 3 & $17 / 209$ & 8.13 \\
\hline & $\mathrm{CA}^{\mathrm{C}}$ & 3 & $15 / 189$ & 7.93 \\
\hline \multirow[t]{6}{*}{$\begin{array}{l}\text { Laboratory } \\
\text { findings }\end{array}$} & $\begin{array}{l}\text { elevated } \\
\text { NTproBNP }\end{array}$ & 11 & $26 / 214$ & 12.2 \\
\hline & High IL-6 & 5 & $5 / 5$ & 100 \\
\hline & $\begin{array}{l}\text { High } \\
\text { D-dimer }\end{array}$ & 5 & $6 / 6$ & 100 \\
\hline & High ferritin & 6 & $6 / 6$ & 100 \\
\hline & High CRPd & 14 & $14 / 201$ & 6.96 \\
\hline & $\begin{array}{l}\text { High } \\
\text { Troponin }\end{array}$ & 18 & $307 / 1412$ & 21.74 \\
\hline
\end{tabular}

$n$, number of patients with any variables; $N$, the total number of studied patients. ${ }^{a} \mathrm{COPD}$, Chronic obstructive pulmonary disease; ${ }^{b} \mathrm{CKD}$, Chronic kidney disease; ${ }^{c} \mathrm{CA}$, Copd/Asthma; ${ }^{d}$ CRP, C-reactive protein.

troponin levels to predict the likelihood of cardiovascular events. Patients with high troponin levels had higher levels of other cardiac biomarkers and more fatal arrhythmias (34).

The results of our analysis revealed that hypertension, obesity, and hyperlipidemia were the most common comorbidities among patients with COVID-19. The association between hypertension and inflammation is well-known; inflammatory responses increase the disease's severity and complications in patients $(64,65)$. In a systematic review study, hypertension was the most common underlying condition in CMPs following COVID-19, reported in $33 \%$ of patients (66). Moreover, the presence of hyperinflammatory conditions in the airways interferes with the virus's clearance (67). It is inferred that the potential synergistic effect of inflammation due to hypertension
TABLE 4 | Cardiomyopathy evidence in patients with COVID-19.

\begin{tabular}{|c|c|c|c|c|}
\hline & Variable & No of study & $n / N$ & $\%$ \\
\hline \multirow[t]{8}{*}{ EKG } & Sinus tachycardia & 7 & $8 / 8$ & 100 \\
\hline & Bradycardia & 2 & $2 / 2$ & 100 \\
\hline & Premature beats & 2 & $4 / 4$ & 100 \\
\hline & ST elevation & 5 & $5 / 5$ & 100 \\
\hline & ST depression & 2 & $2 / 2$ & 100 \\
\hline & Blocks & 2 & $4 / 4$ & 100 \\
\hline & Inverted T wave & 9 & $11 / 12$ & 91.66 \\
\hline & $V T^{\mathrm{a}}$ & 2 & $49 / 1,403$ & 3.49 \\
\hline \multirow{17}{*}{ Echocardiography } & LVE (LVb enlargement) & 3 & $68 / 1,219$ & 5.57 \\
\hline & Mild LV dysfunction & 6 & $208 / 1,216$ & 17.10 \\
\hline & $\begin{array}{l}\text { Moderate LV } \\
\text { dysfunction }\end{array}$ & 4 & $144 / 1,215$ & 11.85 \\
\hline & Severe LV dysfunction & 11 & 122/1,222 & 9.98 \\
\hline & RVE (RVC enlargement) & 1 & $181 / 1,216$ & 14.88 \\
\hline & RV dysfunction & 3 & $315 / 1,211$ & 26.01 \\
\hline & High PAPd & 1 & $99 / 1,216$ & 8.14 \\
\hline & Aneurysm formation & 10 & $11 / 11$ & 100 \\
\hline & $\mathrm{RWMA}^{\mathrm{e}}$ & 10 & $46 / 1,217$ & 1.15 \\
\hline & Pericardial effusion & 3 & $3 / 3$ & 100 \\
\hline & $\mathrm{LVH}^{\mathrm{f}}$ & 4 & $4 / 4$ & 100 \\
\hline & Pericardial effusion & 3 & $3 / 3$ & 100 \\
\hline & Endocarditis & 1 & $14 / 1,216$ & 1.15 \\
\hline & Tamponade & 3 & $13 / 1,218$ & 1.06 \\
\hline & Echo $\mathrm{Ml}^{\mathrm{g}}$ & 2 & $37 / 1,230$ & 3 \\
\hline & Echo Myocarditis & 1 & $35 / 1,216$ & 2.87 \\
\hline & D shap LV & 1 & $49 / 1,216$ & 4.02 \\
\hline \multirow[t]{2}{*}{ CXR } & Diffuse involvement & 6 & $7 / 7$ & 100 \\
\hline & Cardiomegaly & 2 & $2 / 3$ & 66.66 \\
\hline \multirow[t]{2}{*}{ CT scan } & Ground-glass opacities & 11 & $26 / 34$ & 76.47 \\
\hline & Consolidation & 5 & $7 / 7$ & 100 \\
\hline \multirow[t]{2}{*}{ Angiogram } & Abnormal angiogram & 5 & $6 / 7$ & 85.71 \\
\hline & Normal angiogram & 1 & $1 / 1$ & 100 \\
\hline \multirow{7}{*}{$\begin{array}{l}\text { Type of } \\
\text { cardiomyopathy }\end{array}$} & $\mathrm{DCM}^{h}$ & 3 & $71 / 1,225$ & 5.79 \\
\hline & $\mathrm{HCM}^{\mathrm{i}}$ & 3 & $3 / 16$ & 18.75 \\
\hline & Myocarditis & 8 & $55 / 1,229$ & 4.47 \\
\hline & Myocardial injury & 13 & $303 / 1,408$ & 2.3 \\
\hline & Takotsubo & 14 & $32 / 1,222$ & 2.61 \\
\hline & Ischemic after COVID & 1 & $36 / 1,216$ & 2.96 \\
\hline & COVID cardiomyopathy & 3 & $9 / 23$ & 39.13 \\
\hline
\end{tabular}

$n$, number of patients with any variables; N, the total number of studied patients. ${ }^{a} V T$, Ventricular tachycardia; ${ }^{b} L V$, Left ventricular; ${ }^{c} R V$, Right ventricular; ${ }^{d} P A P$, Pulmonary artery pressure; ${ }^{e}$ RWMA, Regional wall motion abnormalities; ${ }^{f} L V H$, Left ventricular hypertrophy; ${ }^{9} \mathrm{M}$, myocardial infarction; ${ }^{h} \mathrm{DCM}$, Dilated cardiomyopathy; ${ }^{i} \mathrm{HCM}$, Hyper trophic cardiomyopathy.

and COVID-19 can aggravate this effect on the heart and result in CMPs.

Studies have shown that obesity is a risk factor for developing ARDS in COVID-19 (68). Moreover, hyperlipidemia has been more prevalent among hospitalized and more severe cases of COVID-19 compared to non-hospitalized ones $(69,70)$.

One of the common diagnostic modalities for COVID-19 is CT-scan. Bilateral and peripheral predominant ground-glass 
TABLE 5 | Treatment agents used in the included studies.

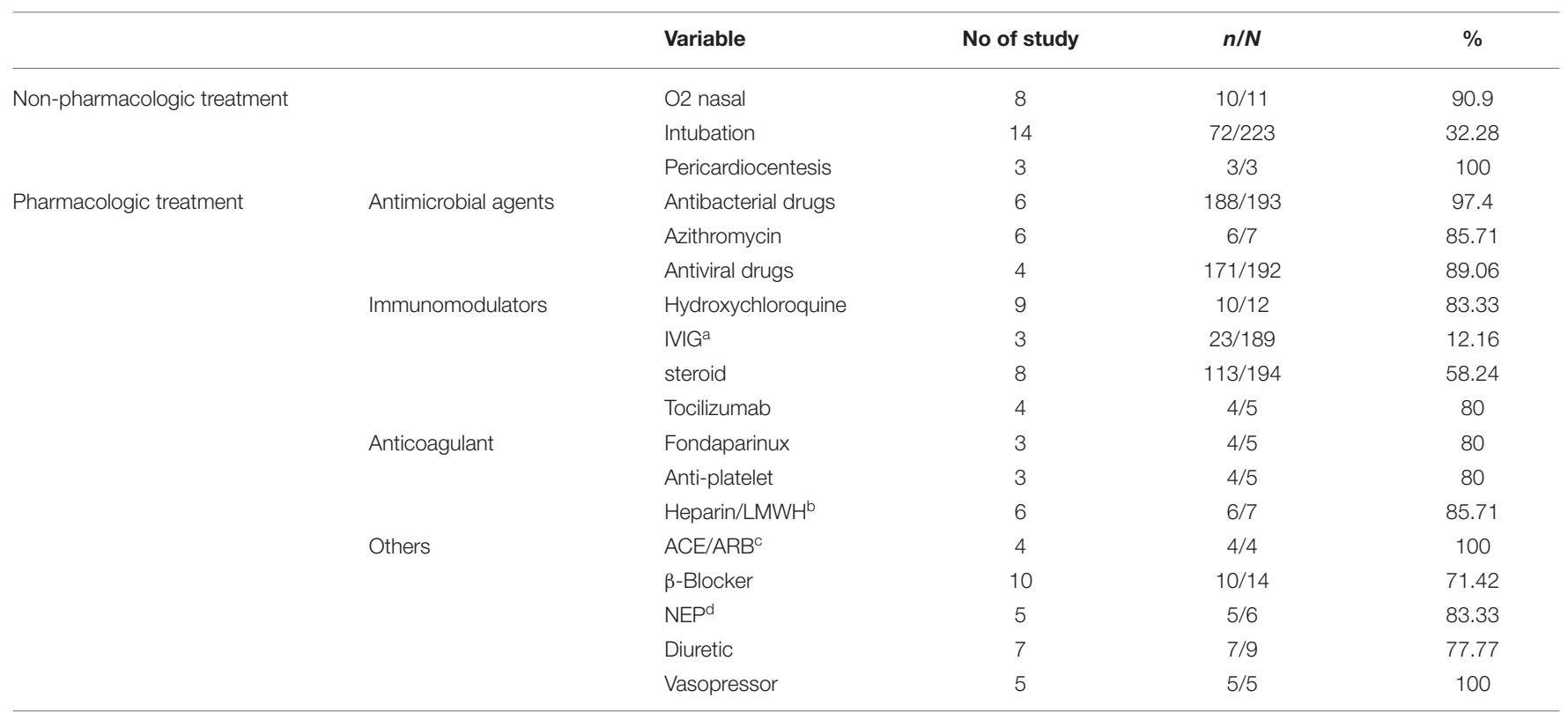

aIVIG, Intravenous immune globulin; ${ }^{b}$ LMWH, Low molecular weight heparin; ${ }^{c}$ ACE/ARB, angiotensin converting enzyme inhibitors/angiotensin-receptor blockers; ${ }^{d}$ NEP, Norepinephrine.

opacity, multifocal patchy consolidation, and interstitial changes with the peripheral distribution are among these features (71).

According to the included articles in our study, $76.47 \%$ of evaluated patients demonstrated Ground-glass opacities in their chest CT scan examination.

Different pharmacological and non-pharmacological treatments have been studied and applied for COVID-19. The included studies showed that nasal oxygen and intubation were among the most common non-pharmacological treatments for patients. Hydroxychloroquine, azithromycin, antiviral drugs, and $\beta$-Blockers were the most common pharmacological treatments. Due to the wide range of disease symptoms and complications, further studies related to each organ involvement are required to manage the disease better and prevent the complications.

In the end, it is necessary to point out the limitations of the present study. Since only case reports and case series studies have been selected for this review, this increases the potential risk of bias. Another issue is the small number of patients enrolled in the study. Due to the scarcity of randomized controlled trial (RCT)/quasi-randomized studies, we could not include them in the present study. We have not adopted the publications as abstracts or letters as data presented in this format is not high quality. Further investigations are required to include a broader range of studies, including clinical trials in patients with COVID-19 and CMPs.

\section{REFERENCES}

1. Dadashi M, Hajikhani B, Yaslianifard S, Goudarzi M, Owlia P, Nasiri MJ, et al. COVID-19 and Skin manifestations: An overview of case reports/case series and meta-analysis of the prevalence studies. Front Med. (2020) 7:573188. doi: $10.3389 /$ fmed.2020.573188
In conclusion, cardiac injury and CMPs, including exacerbation of an underlying CMPs or the emergence of new CMPs, are common in COVID-19 patients. Moreover, they are associated with higher mortality and morbidity in these patients. Common fatal conditions in patients with COVID-19 CMPs include multiorgan damage, ARDS, and cardiogenic shock. Therefore, diagnostic measures of COVID-19 should consist of underlying cardiovascular comorbidities. History, signs, and symptoms of cardiac injury should be considered in evaluating these patients early in the course of this novel disease, and prompt therapeutic measures for the prevention of exacerbating cardiac condition should be sought.

\section{DATA AVAILABILITY STATEMENT}

The original contributions presented in the study are included in the article/supplementary material, further inquiries can be directed to the corresponding author/s.

\section{AUTHOR CONTRIBUTIONS}

FO, MN, and BH: designed the study. FO, SK, AT, SR, AA, $\mathrm{SH}, \mathrm{MG}$, and FK: performed the search, study selection, and data synthesis. $\mathrm{BH}, \mathrm{FO}$, and $\mathrm{MN}$ : wrote the first draft of the manuscript. $\mathrm{MN}, \mathrm{BH}$, and MM: revised the article. All authors contributed to the paper and approved the submitted version.

2. Hajikhani B, Calcagno T, Nasiri MJ, Jamshidi P, Dadashi M, Goudarzi M, et al. Olfactory and gustatory dysfunction in COVID-19 patients: A meta-analysis study. Physiol Rep. (2020) 8:e14578. doi: 10.14814/phy2.14578

3. Inciardi RM, Lupi L, Zaccone G, Italia L, Raffo M, Tomasoni D, et al. Cardiac involvement in a patient with coronavirus disease 2019 (COVID-19). JAMA Cardiol. (2020) 5:819-24. doi: 10.1001/jamacardio.2020.1096 
4. Shi S, Qin M, Shen B, Cai Y, Liu T, Yang F, et al. Association of cardiac injury with mortality in hospitalized patients with COVID-19 in Wuhan, China. JAMA Cardiol. (2020) 5:802-10. doi: 10.1001/jamacardio.2020.0950

5. Cizgici AY, Agus HZ, Yildiz M. COVID-19 myopericarditis: it should be kept in mind in today's conditions. Am J Emerg Med. (2020) 38:1547.e51547.e6. doi: 10.1016/j.ajem.2020.04.080

6. Ruan Q, Yang K, Wang W, Jiang L, Song J. Clinical predictors of mortality due to COVID-19 based on an analysis of data of 150 patients from Wuhan, China. Intensive Care Med. (2020) 46:846-8. doi: 10.1007/s00134-020-05991-x

7. Pérez-Bermejo JA, Kang S, Rockwood SJ, Simoneau CR, Joy DA, Ramadoss GN, et al. SARS-CoV-2 infection of human iPSC-derived cardiac cells predicts novel cytopathic features in hearts of COVID-19 patients. BioRxiv [Preprint]. (2020). doi: 10.1101/2020.08.25.265561

8. Siripanthong B, Nazarian S, Muser D, Deo R, Santangeli P, Khanji MY, et al. Recognizing COVID-19-related myocarditis: The possible pathophysiology and proposed guideline for diagnosis and management. Heart Rhythm. (2020) 17:1463-71. doi: 10.1016/j.hrthm.2020.05.001

9. Shafi AM, Shaikh SA, Shirke MM, Iddawela S, Harky A. Cardiac manifestations in COVID-19 patients-A systematic review. J Cardiac Surg. (2020) 35:1988-2008. doi: 10.1111/jocs.14808

10. Limongelli G, Crotti L. COVID-19 pandemia and inherited cardiomyopathies and channelopathies: a short term and long term perspective. Orphanet J Rare Dis. (2020) 15:1-7. doi: 10.1186/s13023-020-01444-2

11. Madjid M, Safavi-Naeini P, Solomon SD, Vardeny O. Potential effects of coronaviruses on the cardiovascular system: a review. JAMA Cardiol. (2020) 5:831-40. doi: 10.1001/jamacardio.2020.1286

12. Nasiri MJ, Haddadi S, Tahvildari A, Farsi Y, Arbabi M, Hasanzadeh S, et al. COVID-19 clinical characteristics, and sex-specific risk of mortality: systematic review and meta-analysis. Front Med. (2020) 7:459. doi: 10.3389/fmed.2020.00459

13. Tahvildari A, Arbabi M, Farsi Y, Jamshidi P, Hasanzadeh S, Calcagno TM, et al. Clinical features, diagnosis, and treatment of COVID-19 in hospitalized patients: a systematic review of case reports and case series. Front Med. (2020) 7:231. doi: 10.3389/fmed.2020.00231

14. Vetter P, Vu DL, L'Huillier AG, Schibler M, Kaiser L, Jacquerioz F. Clinical features of covid-19. Br Med J Publishing Group. (2020) 369:m1470. doi: 10.1136/bmj.m1470

15. Marini JJ, Gattinoni L. Management of COVID-19 respiratory distress. JAMA. (2020) 323:2329-30. doi: 10.1001/jama.2020.6825

16. Ziehr DR, Alladina J, Petri CR, Maley JH, Moskowitz A, Medoff BD, et al. Respiratory pathophysiology of mechanically ventilated patients with COVID-19: a cohort study. Am J Respirat Crit Care Med. (2020) 201:15604. doi: 10.1164/rccm.202004-1163LE

17. Gattinoni L, Chiumello D, Caironi P, Busana M, Romitti F, Brazzi L, et al. COVID-19 pneumonia: different respiratory treatments for different phenotypes?. Intensive Care Med. (2020) 46:1099-102. doi: 10.1007/s00134-020-06033-2

18. Knobloch K, Yoon U, Vogt PM. Preferred reporting items for systematic reviews and meta-analyses (PRISMA) statement and publication bias. $J$ Cranio-Maxillofacial Surg. (2011) 39:91-2. doi: 10.1016/j.jcms.2010.11.001

19. Doyen D, Moceri P, Ducreux D, Dellamonica J. Myocarditis in a patient with COVID-19: a cause of raised troponin and ECG changes. Lancet. (2020) 395:1516. doi: 10.1016/S0140-6736(20)30912-0

20. Paul J-F, Charles P, Richaud C, Caussin C, Diakov C. Myocarditis revealing COVID-19 infection in a young patient. Eur Heart J Cardiovasc Imaging. (2020) 21:776. doi: 10.1093/ehjci/jeaa107

21. Huyut MA. Novel coronavirus pneumonia and cardiomyopathy: a case report. Arq Bras Cardiol. (2020) 114:843-5. doi: 10.36660/abc.20200268

22. Pasqualetto MC, Secco E, Nizzetto M, Scevola M, Altafini L, Cester A, et al. Stress cardiomyopathy in COVID-19 Disease. Eur J Case Rep Internal Med. (2020) 7:001718. doi: 10.12890/2020_001718

23. Deng Q, Hu B, Zhang Y, Wang H, Zhou X, Hu W, et al. Suspected myocardial injury in patients with COVID-19: Evidence from front-line clinical observation in Wuhan, China. Int J Cardiol. (2020) 311:11621. doi: 10.1016/j.ijcard.2020.03.087

24. Taza F, Zulty M, Kanwal A, Grove D. Takotsubo cardiomyopathy triggered by SARS-CoV-2 infection in a critically ill patient. BMJ Case Rep CP. (2020) 13:e236561. doi: 10.1136/bcr-2020-236561
25. Roca E, Lombardi C, Campana M, Vivaldi O, Bigni B, Bertozzi B, et al. Takotsubo syndrome associated with COVID-19. Eur J Case Rep Internal Med. (2020) 7:1665. doi: 10.12890/2020_001665

26. Minhas AS, Scheel P, Garibaldi B, Liu G, Horton M, Jennings M, et al. Takotsubo syndrome in the setting of COVID-19 infection. JACC: Case Rep. (2020) 2:1321-5. doi: 10.1016/j.jaccas.2020.04.023

27. Juusela A, Nazir M, Gimovsky M. Two cases of COVID-19 related cardiomyopathy in pregnancy. Am J Obstetri Gynecol MFM. (2020) 2:100113. doi: 10.1016/j.ajogmf.2020.100113

28. Meyer P, Degrauwe S, Van Delden C, Ghadri J-R, Templin C. Typical takotsubo syndrome triggered by SARS-CoV-2 infection. Euro Heart J. (2020) 41:1860. doi: 10.1093/eurheartj/ehaa306

29. Khalid Y, Dasu N, Dasu K. A case of novel coronavirus (COVID-19)-induced viral myocarditis mimicking a Takotsubo cardiomyopathy. HeartRhythm Case Rep. (2020) 6:473. doi: 10.1016/j.hrcr.2020.05.020

30. Nguyen D, Nguyen T, De Bels D, Rodriguez JC. A case of Takotsubo cardiomyopathy with COVID 19. Euro Heart J Cardiovasc Imaging. (2020) 21:1052. doi: 10.1093/ehjci/jeaa152

31. Bonnet M, Craighero F, Harbaoui B. Acute myocarditis with ventricular non compaction in a COVID-19 patient. Jacc Heart Failure. (2020) 8:599600. doi: 10.1016/j.jchf.2020.05.004

32. Zhang L, Wang B, Zhou J, Kirkpatrick J, Xie M, Johri AM. Bedside focused cardiac ultrasound in COVID-19 from the Wuhan epicenter: the role of cardiac point-of-care ultrasound, limited transthoracic echocardiography, and critical care echocardiography. J Am Soc Echocardiography. (2020) 33:676-82. doi: 10.1016/j.echo.2020.04.004

33. Dabbagh MF, Aurora L, D’Souza P, Weinmann AJ, Bhargava P, Basir MB. Cardiac tamponade secondary to COVID-19. JACC: Case Rep. (2020) 2:132630. doi: 10.1016/j.jaccas.2020.04.009

34. Guo $\mathrm{T}$, Fan $\mathrm{Y}$, Chen $\mathrm{M}$, Wu $\mathrm{X}$, Zhang $\mathrm{L}, \mathrm{He} \mathrm{T}$, et al. Cardiovascular implications of fatal outcomes of patients with coronavirus disease 2019 (COVID-19). JAMA Cardiol. (2020) 5:811-8. doi: 10.1001/jamacardio.2020.1017

35. Tavazzi G, Pellegrini C, Maurelli M, Belliato M, Sciutti F, Bottazzi A, et al. Myocardial localization of coronavirus in COVID-19 cardiogenic shock. Eur J Heart Failure. (2020) 22:911-5. doi: 10.1002/ejhf.1828

36. Hua A, O'Gallagher K, Sado D, Byrne J. Life-threatening cardiac tamponade complicating myo-pericarditis in COVID-19. Eur Heart J. (2020) 41:2130. doi: 10.1093/eurheartj/ehaa253

37. Villanueva D-DH, Lusby HP, Islam SP, Gupte AA, Beatty NL. Heart failure exacerbation as only presenting sign of COVID-19. IDCases. (2020) 21:e00870. doi: 10.1016/j.idcr.2020.e00870

38. Kir D, Mohan C, Sancassani R. Heart brake: an unusual cardiac manifestation of COVID-19. JACC: Case Rep. (2020) 2:1252-5. doi: 10.1016/j.jaccas.2020.04.026

39. Dweck MR, Bularga A, Hahn RT, Bing R, Lee KK, Chapman AR, et al. Global evaluation of echocardiography in patients with COVID-19. Eur Heart J Cardiovasc Imaging. (2020) 21:949-58. doi: 10.1093/ehjci/jeaa178

40. Irabien-Ortiz Á, Carreras-Mora J, Sionis A, Pàmies J, Montiel J, Tauron M. Fulminant myocarditis due to COVID-19. Rev Española Cardiol. (2020) 73:503-4. doi: 10.1016/j.rec.2020.04.005

41. Craver R, Huber S, Sandomirsky M, McKenna D, Schieffelin J, Finger L. Fatal eosinophilic myocarditis in a healthy 17 -year-old male with severe acute respiratory syndrome coronavirus 2 (SARS-CoV-2c). Fetal Pediatr Pathol. (2020) 39:26-8. doi: 10.1080/15513815.2020.1761491

42. Bobeck KA, Holtzclaw AW, Brown TE, Clark PA. Effective use of angiotensin ii in coronavirus disease 19-associated mixed shock state: a case report. A\&a Practice. (2020) 14:e01221. doi: 10.1213/XAA.00000000000 01221

43. Arentz M, Yim E, Klaff L, Lokhandwala S, Riedo FX, Chong M, et al. Characteristics and outcomes of 21 critically ill patients with COVID19 in Washington State. JAMA. (2020) 323:1612-4. doi: 10.1001/jama. 2020.4326

44. Yildirim AI, Karaagac AT. COVID-19 in a Young Girl with Restrictive Cardiomyopathy and Chronic Lung Disease. Indian Pediatri. (2020) 57:577. doi: 10.1007/s13312-020-1863-1

45. Chadha S. 'COVID-19 Pandemic'Anxiety induced Tako-tsubo Cardiomyopathy. QJM. (2020) 113:488-90. doi: 10.1093/qjmed/hcaa135 
46. Kim I-C, Kim JY, Kim HA, Han S. COVID-19-related myocarditis in a 21-year-old female patient. Eur Heart J. (2020) 41:1859. doi: 10.1093/eurheartj/ehaa288

47. Luetkens JA, Isaak A, Zimmer S, Nattermann J, Sprinkart AM, Boesecke C, et al. Diffuse myocardial inflammation in COVID19 associated myocarditis detected by multiparametric cardiac magnetic resonance imaging. Circulation: Cardiovasc Imaging. (2020) 13:e010897. doi: 10.1161/CIRCIMAGING.120.010897

48. Bonow RO, Fonarow GC, O'Gara PT, Yancy CW. Association of coronavirus disease 2019 (COVID-19) with myocardial injury and mortality. JAMA Cardiol. (2020) 5:751-3. doi: 10.1001/jamacardio.2020.1105

49. Zheng Y-Y, Ma Y-T, Zhang J-Y, Xie X. COVID-19 and the cardiovascular system. Nat Rev Cardiol. (2020) 17:259-60. doi: 10.1038/s41569-020-0360-5

50. Zhou F, Yu T, Du R, Fan G, Liu Y, Liu Z, et al. Clinical course and risk factors for mortality of adult inpatients with COVID-19 in Wuhan, China: a retrospective cohort study. Lancet. (2020) 395:105462. doi: 10.1016/S0140-6736(20)30566-3

51. Xu X-W, Wu X-X, Jiang X-G, Xu K-J, Ying L-J, Ma C-L, et al. Clinical findings in a group of patients infected with the 2019 novel coronavirus (SARS-Cov-2) outside of Wuhan, China: retrospective case series. Bmj. (2020) 368:m606. doi: 10.1136/bmj.m606

52. Yang X, Yu Y, Xu J, Shu H, Liu H, Wu Y, et al. Clinical course and outcomes of critically ill patients with SARS-CoV-2 pneumonia in Wuhan, China: a single-centered, retrospective, observational study. Lancet Respirat Med. (2020) 8:475-81. doi: 10.1016/S2213-2600(20)30079-5

53. Huang C, Wang Y, Li X, Ren L, Zhao J, Hu Y, et al. Clinical features of patients infected with 2019 novel coronavirus in Wuhan, China. Lancet. (2020) 395:497-506. doi: 10.1016/S0140-6736(20)30183-5

54. Mahallawi WH, Khabour OF, Zhang Q, Makhdoum HM, Suliman BA. MERSCoV infection in humans is associated with a pro-inflammatory Th1 and Th17 cytokine profile. Cytokine. (2018) 104:8-13. doi: 10.1016/j.cyto.2018.01.025

55. Lang JP, Wang X, Moura FA, Siddiqi HK, Morrow DA, Bohula EA. A current review of COVID-19 for the cardiovascular specialist. Am Heart J. (2020) 226:29-44. doi: 10.1016/j.ahj.2020.04.025

56. Bemtgen X, Krüger K, Supady A, Duerschmied D, Schibilsky D, Bamberg F, et al. First successful treatment of coronavirus disease 2019 induced refractory cardiogenic plus vasoplegic shock by combination of percutaneous ventricular assist device and extracorporeal membrane oxygenation: a case report. Asaio J. (2020) 66:607-9. doi: 10.1097/MAT.0000000000001178

57. Tan W, Aboulhosn J. The cardiovascular burden of coronavirus disease 2019 (COVID-19) with a focus on congenital heart disease. Int J Cardiol. (2020) 309:70-7. doi: 10.1016/j.ijcard.2020.03.063

58. Fried JA, Ramasubbu K, Bhatt R, Topkara VK, Clerkin KJ, Horn E, et al. The variety of cardiovascular presentations of COVID-19. Circulation. (2020) 141:1930-6. doi: 10.1161/CIRCULATIONAHA.120.047164

59. Driggin E, Madhavan MV, Bikdeli B, Chuich T, Laracy J, Biondi-Zoccai G, et al. Cardiovascular considerations for patients, health care workers, and health systems during the COVID-19 pandemic. J Am College Cardiol. (2020) 75:2352-71. doi: 10.1016/j.jacc.2020.03.031

60. Harari R, Bangalore S, Chang E, Shah B. COVID-19 complicated by acute myocardial infarction with extensive thrombus burden and cardiogenic shock. Catheterization Cardiovasc Interven. (2020) 97:E6616. doi: $10.1002 / \mathrm{ccd} .28992$

61. Chen G, Wu D, Guo W, Cao Y, Huang D, Wang H, et al. Clinical and immunologic features in severe and moderate forms of coronavirus disease. J Clin Invest. (2019) 130:2620-9. doi: 10.1172/JCI137244

62. Gao Y, Li T, Han M, Li X, Wu D, Xu Y, et al. Diagnostic utility of clinical laboratory data determinations for patients with the severe COVID-19. J Med Virol. (2020) 92:791-6. doi: 10.1002/jmv.25770

63. Mouhat B, Besutti M, Bouiller K, Grillet F, Monnin C, Ecarnot F, et al. Elevated D-dimers and lack of anticoagulation predict PE in severe COVID-19 patients. Eur Respirat J. (2020) 56:2001811. doi: 10.1183/13993003.01811-2020

64. Jayedi A, Rahimi K, Bautista LE, Nazarzadeh M, Zargar MS, Shab-Bidar S. Inflammation markers and risk of developing hypertension: a meta-analysis of cohort studies. Heart. (2019) 105:686-92. doi: 10.1136/heartjnl-2018-314216

65. McMaster WG, Kirabo A, Madhur MS, Harrison DG. Inflammation, immunity, and hypertensive end-organ damage. Circulat Res. (2015) 116:1022-33. doi: 10.1161/CIRCRESAHA.116.303697

66. Sawalha K, Abozenah M, Kadado AJ, Battisha A, Al-Akchar M, Salerno C, et al. Systematic review of COVID-19 related myocarditis: Insights on management and outcome. Cardiovasc Revasculariz Med. (2020) 23:10713. doi: $10.1016 /$ j.carrev.2020.08.028

67. Trump S, Lukassen S, Anker MS, Chua RL, Liebig J, Thürmann L, et al. Hypertension delays viral clearance and exacerbates airway hyperinflammation in patients with COVID-19. Nat Biotechnol. (2020). doi: 10.1038/s41587-020-00796-1. [Epub ahead of print].

68. Gong MN, Bajwa EK, Thompson BT, Christiani DC. Body mass index is associated with the development of acute respiratory distress syndrome. Thorax. (2010) 65:44-50. doi: 10.1136/thx.2009.117572

69. Iqbal Z, Ho JH, Adam S, France M, Syed A, Neely D, et al. Managing hyperlipidaemia in patients with COVID-19 and during its pandemic: An expert panel position statement from HEART UK. Atherosclerosis. (2020) 313:126-36. doi: 10.1016/j.atherosclerosis.2020.09.008

70. Wei X, Zeng W, Su J, Wan H, Yu X, Cao X, et al. Hypolipidemia is associated with the severity of COVID-19. J Clin Lipidol. (2020) 14:297304. doi: 10.1016/j.jacl.2020.04.008

71. Nouri E, Delashoub O, Shahabi-Rabori MA, Afzalipour R, Jafari S. Interpretation of CT scan findings during the COVID-19 pandemic. Hormozgan Med J. (2020) 24:107909. doi: 10.5812/hmj.107909

Conflict of Interest: The authors declare that the research was conducted in the absence of any commercial or financial relationships that could be construed as a potential conflict of interest.

Copyright (C) 2021 Omidi, Hajikhani, Kazemi, Tajbakhsh, Riazi, Mirsaeidi, Ansari, Ghanbari Boroujeni, Khalili, Hadadi and Nasiri. This is an open-access article distributed under the terms of the Creative Commons Attribution License (CC BY). The use, distribution or reproduction in other forums is permitted, provided the original author(s) and the copyright owner(s) are credited and that the original publication in this journal is cited, in accordance with accepted academic practice. No use, distribution or reproduction is permitted which does not comply with these terms. 